\title{
Facilitatory Actions of Guanidine on Synaptic Transmission in Mammalian Brain Slices
}

\author{
M. Galvan, P. Grafe, and G. Ten Bruggencate ${ }^{1}$ \\ Department of Physiology, University of Munich, Pettenkoferstrasse 12, 8000 München 2, \\ German Federal Republic
}

Received July 30,1979

\begin{abstract}
Guanidine administration may be beneficial in the treatment of amyotrophic lateral sclerosis and related diseases; however, the actions of guanidine on the mammalian central nervous system have not been investigated. We studied the effects of this compound on neuronal properties and synaptic transmission in isolated slices of guinea pig olfactory cortex using intra- and extracellular recording methods. Addition of guanidine to the superfusate $(\geqslant 300 \mu \mathrm{M})$ produced the following effects. (a) Excitatory and inhibitory postsynaptic potentials, evoked by stimulation of the lateral olfactory tract, were increased in amplitude and duration; (b) the amplitude and frequency of spontaneously occurring postsynaptic potentials was significantly increased; (c) membrane potential and input resistance remained virtually unchanged; and (d) the duration of the lateral olfactory tract compound action potential was prolonged. These results suggest that guanidine enhances the release of excitatory and inhibitory neurotransmitters in the mammalian cortex and this effect may be beneficial in human central nervous system diseases in which the efficiency of synaptic transmission is reduced.
\end{abstract}

\section{INTRODUCTION}

Effects of guanidine on the peripheral and central nervous system were first described more than 100 years ago (7). Since then, the actions of guanidine on transmission at the neuromuscular junction of frogs $(5,16,18$, $22)$, mammals $(9,15,30)$, and even humans $(10,11)$ have been investigated in detail. Those studies revealed that guanidine facilitated the release of neurotransmitter from presynaptic terminals and this action was shown to

Abbreviations: LOT-lateral olfactory tract: EPSP, IPSP - excitatory, inhibitory postsynaptic potential; TTX - tetrodotoxin.

${ }^{1}$ We wish to thank Mr. K. Zinnhobler for assistance with the computer analysis. This work was supported by the Deutsche Forschungsgemeinschaft, grant $\mathrm{Br}$. 242/14. 
be of use in the treatment of some human disorders of neuromuscular transmission, such as botulism $(3,24)$ and the myasthenic syndrome $(14,21)$.

The description of facilitatory actions on neuromuscular transmission led to the trial of guanidine as a treatment for patients suffering from degenerative diseases of the central nervous system (20). Although these trials are still preliminary (31), there is some evidence to suggest that guanidine treatment can slow the progress of diseases such as amyotrophic lateral sclerosis $(17,20)$ and spinal muscular atrophy (29). However, the mechanism of action of guanidine on the central nervous system has been only partially investigated. Administration of the drug was reported to have the following effects: (a) an augmentation of spontaneous and stimulusinduced potentials in ventral and dorsal roots of the cat spinal cord (13); (b) an increased amplitude and frequency of spontaneous postsynaptic potentials, and an enhancement of stimulus-induced postsynaptic potentials recorded from motoneurons in the frog spinal cord (8); and (c) an increase in the excitability of single axons in the lamprey spinal cord (18).

The present experiments were undertaken to obtain more information about the effects of guanidine on the mammalian central nervous system, and perhaps to provide some explanation for its beneficial effects in degenerative nervous diseases. We studied the actions of guanidine on synaptic transmission in the guinea pig isolated olfactory cortex and on conduction along the isolated lateral olfactory tract. A preliminary report of these results has been presented (6).

\section{METHODS}

Guinea pigs of either sex weighing 300 to $400 \mathrm{~g}$ were decapitated and surface slices of olfactory cortex approximately $0.5 \mathrm{~mm}$ thick were cut by hand using a razor blade and recessed Perspex guide (26). Slices were maintained at $25^{\circ} \mathrm{C}$ in Krebs's solution of the following composition (mM): $\mathrm{NaCl}, 118 ; \mathrm{KCl}, 1.8 ; \mathrm{NaHCO}_{3}, 25 ; \mathrm{KH}_{2} \mathrm{PO}_{4}, 1.2 ; \mathrm{MgSO}_{4}, 1.2 ; \mathrm{CaCl}_{2}, 2.5$; $\mathrm{D}$-glucose, 11 . In all experiments drugs were added in fixed concentrations to the incubation medium and all solutions were equilibrated with $95 \%$ $\mathrm{O}_{2}-5 \% \mathrm{CO}_{2}$. For intracellular recording, slices were placed in a small bath and superfused at a rate of about $5 \mathrm{ml} / \mathrm{min}$. Recordings were obtained from neurons in the prepyriform or periamygdaloid regions using a single microelectrode ( 80 to $120 \mathrm{M} \Omega$ ) filled with $4 \mathrm{M}$ potassium acetate buffered to $p \mathrm{H} 7.4$ with acetic acid (26). Neurons were orthodromically stimulated (20 to $40 \mathrm{~V}, 0.3 \mathrm{~ms}$ ) via a pair of platinum electrodes placed across the cut end of the lateral olfactory tract. Only cells with initial resting membrane potentials of $>50 \mathrm{mV}$ were selected and potentials were displayed on an oscilloscope and chart recorder. In addition, data were stored on magnetic 
tape for subsequent analysis. A Nicolet Med 80 computer was used to count spontaneously occurring postsynaptic potentials.

Extracellular field potentials were recorded using $\mathrm{Ag} / \mathrm{AgCl}$ electrodes and differential recording as described by Brown and Galvan (2).

In a number of experiments, slices approximately $0.3 \mathrm{~mm}$ thick were cut and the lateral olfactory tract was then dissected free of the surrounding cortex. The central end was drawn into a suction electrode and the peripheral end was stimulated intermittently with rectangular pulses $(0.1$ $\mathrm{ms}$, submaximal voltage). The nerve fiber population action potential recorded from the suction electrode was displayed on an oscilloscope (AC coupled) and potentials were averaged using a signal averager (Didac 400).

The drug sources were guanidine hydrochloride, Merck; tetrodotoxin, Calbiochem.

\section{RESULTS}

\section{Intracellular Recording}

Intracellular recordings were obtained from 16 neurons in 12 slices and guanidine was applied to the bathing solution in concentrations of $500 \mu \mathrm{M}$ to $5 \mathrm{~mm}$. In the guanidine solution, synaptically evoked potentials were clearly prolonged in duration and either increased or decreased in amplitude. In addition, there was a marked increase in the amplitude and frequency of spontaneously occurring, postsynaptic potentials. Changes in membrane potential and apparent input resistance were small and sometimes absent. The effects of guanidine were slow in onset and therefore the drug was applied for 10 to $60 \mathrm{~min}$.

Stimulus-Induced Postsynaptic Potentials. Figure 1 shows examples of lateral olfactory tract evoked postsynaptic potentials recorded before and during application of guanidine. Orthodromic activation of olfactory cortex neurons by stimulation of the lateral olfactory tract (LOT) normally produced the following sequence of postsynaptic potentials (Fig. 1A): an excitatory postsynaptic potential (EPSP, duration about $30 \mathrm{~ms}$ ) with a single action potential. This was followed by a slowly decaying (about 150 ms) depolarizing potential, which had the properties of an inhibitory postsynaptic potential [IPSP, (27)]. In the control solution, the complete orthodromic response lasted about $200 \mathrm{~ms}$, but in guanidine solution this was increased to between 500 and $1000 \mathrm{~ms}$ (eight neurons tested, see Figs. 1A-D).

Simple prolongation of LOT-evoked potentials was not the only effect of guanidine. Some cells exhibited "afterdischarges" an example of which is shown in Fig. IF. Such afterdischarges or rhythmic oscillations of the 

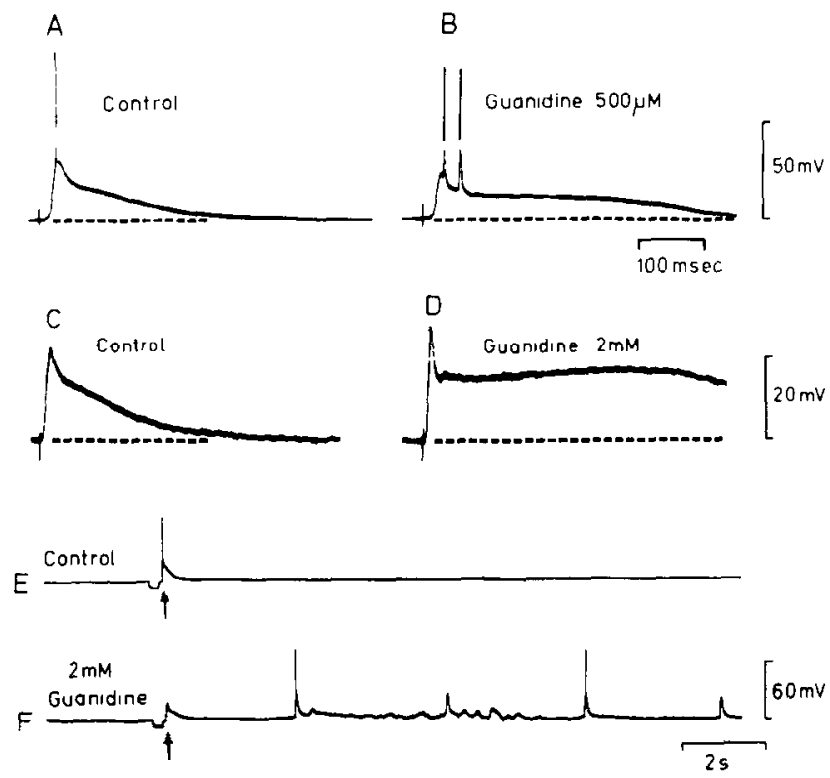

Fig. 1. Effects of guanidine on orthodromically evoked postsynaptic potentials (PSP) recorded from neurons in the olfactory cortex. A, C, and E are controls taken from three different experiments. B (stimulation frequency $0.025 \mathrm{~Hz}$ ) shows one lateral olfactory tract-evoked PSP after $60 \mathrm{~min}$ in $500 \mu \mathrm{M}$ guanidine; note the decreased excitatory postsynaptic potential amplitude, double spike, and the prolonged duration. In $D(0.017 \mathrm{~Hz})$, recorded after $10 \mathrm{~min}$ in $2 \mathrm{mM}$ guanidine, the EPSP amplitude was clearly increased. $\mathrm{F}(0.025$ $\mathrm{Hz}$ ) illustrates an example of spontaneous afterdischarges after a single lateral olfactory tract stimulus (arrow) recorded after $37 \mathrm{~min}$ in $2 \mathrm{~mm}$ guanidine solution. Dashed line in all records indicates projected baseline; spikes retouched in $E$ and $F$.

membrane potential after a single LOT stimulus were typical effects of higher concentrations of guanidine ( $\geqslant 2 \mathrm{~mm}$ ).

We also observed changes in the amplitude of the LOT-evoked potentials; in two cells guanidine clearly increased the amplitude of the EPSP (Fig. 1D), whereas in the other six cells there was either a decrease (Fig. 1B) or no effect.

Spontaneous Postsynaptic Potentials. Figure 2 illustrates spontaneous postsynaptic potentials and LOT-evoked synaptic potentials before and during exposure to $2 \mathrm{~mm}$ guanidine. In the control solution, spontaneous depolarizing postsynaptic potentials a few millivolts in amplitude could be observed. Addition of guanidine increased the amplitude and frequency of spontaneously occurring potentials in this and 10 other neurons of the 16 tested. Figure 2 also illustrates that the increase in spontaneous postsynaptic activity was accompanied by a prolongation of the LOT-evoked postsynaptic potential. When tetrodotoxin (TTX, $10^{-7} \mathrm{~g} / \mathrm{ml}$ ) 


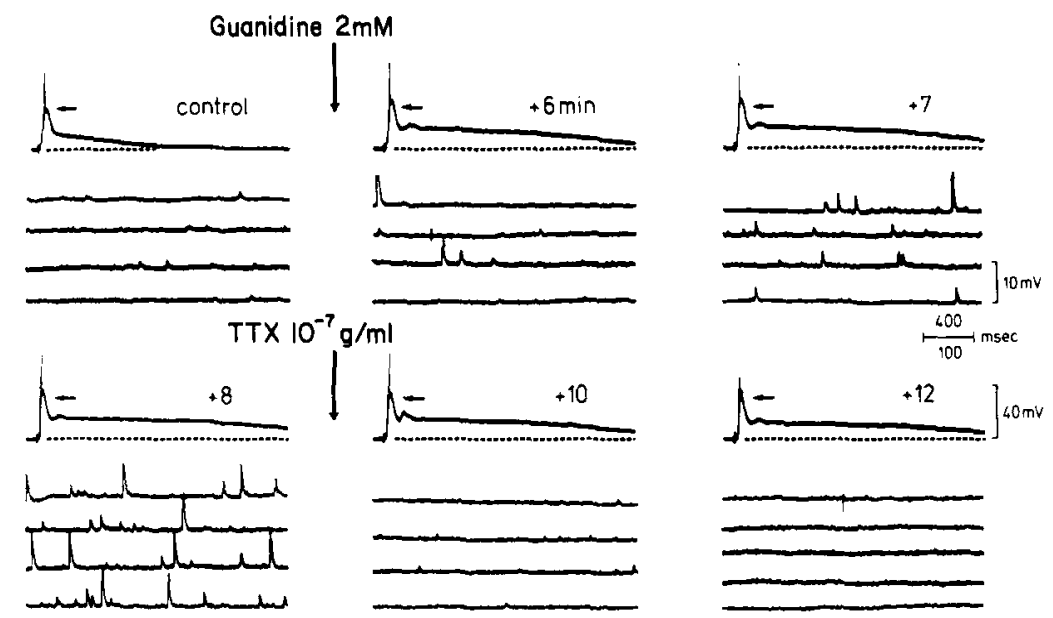

Fig. 2. Effect of $2 \mathrm{~mm}$ guanidine on orthodromic transmission and spontaneous postsynaptic potentials. In each panel the top line shows the response to a single orthodromic stimulus $(30 \mathrm{~V}, 0.3 \mathrm{~ms}, 0.017 \mathrm{~Hz})$ and the lower lines are high-amplification oscilloscope records of the membrane potential. The numbers above each panel show the time (min) after adding guanidine; tetrodotoxin (TTX) was added to the medium 9 min after guanidine. Note that in the control there are several low-amplitude spontaneous potentials, the amplitude and frequency of which were greatly enhanced by guanidine. Additionally, the duration of the orthodromic responses was significantly prolonged (dashed line indicates projected baseline) and the amplitude of the excitatory postsynaptic potential was increased (horizontal arrow indicates control amplitude). TTX abolished all spontaneous activity and blocked the action potential. Time calibration: $400 \mathrm{~ms}$ for spontaneous activity: $100 \mathrm{~ms}$ for orthodromic responses.

was added to the superfusate, all spontaneous potentials were abolished within a few minutes and the orthodromic action potential was blocked.

The effect of guanidine on spontaneous potentials was not immediate in onset and was both time- and concentration-dependent. Figure 3 specifically illustrates this point and shows that low concentrations (about 1 $\mathrm{mM})$ required longer application times to induce modest increases in spontaneous activity whereas higher concentrations ( 2 to $5 \mathrm{~mm}$ ) usually produced massive increases in activity after only a few minutes. When an increase in spontaneous activity has been induced, it persisted for many minutes despite removing guanidine from the superfusate (Fig. 3). Spontaneous potentials had a duration of about $50 \mathrm{~ms}$ and although they sometimes reached an amplitude of $10 \mathrm{mV}$ or more, they did not usually elicit action potentials.

Guanidine-induced spontaneous activity could be rapidly abolished by addition of either $15 \mathrm{mM} \mathrm{MgCl}$ (three cells tested; Fig. 5) or tetrodotoxin $10^{-7} \mathrm{~g} / \mathrm{ml}$ (four cells tested; Fig. 2). 


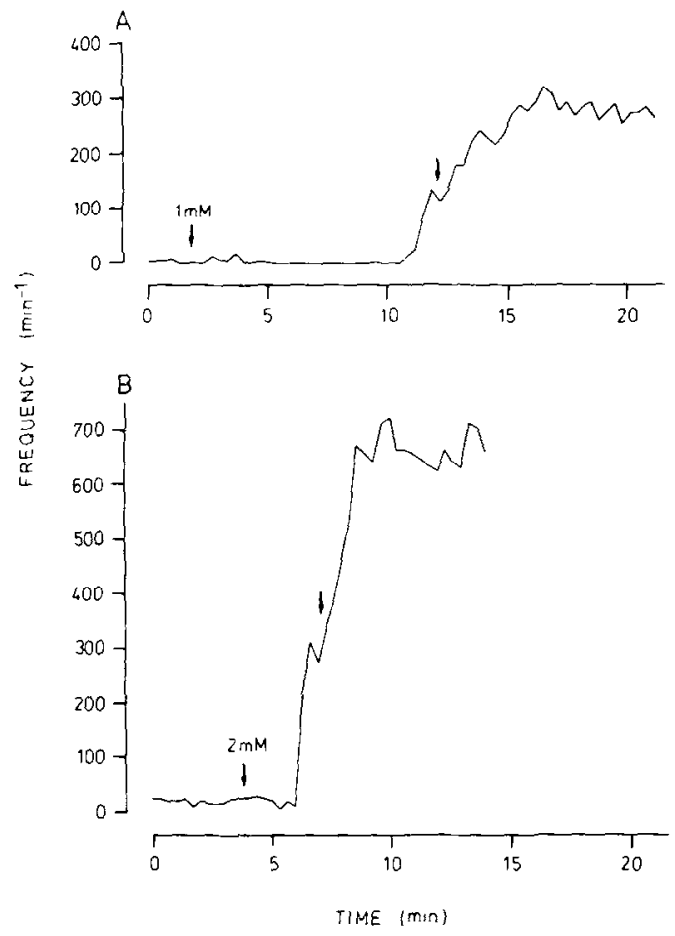

FIG. 3. Computer plot of the effect of (A) 1 and (B) $2 \mathrm{~mm}$ guanidine on the frequency of spontaneously occurring postsynaptic potentials. Ordinates show the number of spontaneous potentials per minute; abscissae show the time from the start of recording. The vertical arrows indicate the duration of drug application. $A$ and $B$ were recorded from different cells in different slices.

Membrane Potential and Resistance. The effects of guanidine ( $500 \mu \mathrm{M}$ to ? $\mathrm{mM}$ ) on membrane potential and neuron apparent input resistance are iummarized in Table 1. No clear changes in the membrane potential were sbserved during the first few minutes of guanidine application and esistance changes were small and inconsistent. Figure 4 shows the :urrent-voltage relationship of one cell before, and $40 \mathrm{~min}$ after the pplication of $2 \mathrm{~mm}$ guanidine. During this time, the cell depolarized $1 \mathrm{mV}$ nd its resistance was only slightly increased.

Sometimes it was noted that during long drug applications, there were mall depolarizations and decreases in resistance (Fig. 5). These effects ccurred at approximately the same time as the spontaneous activity was eginning to increase and could be reversed by application of $\mathrm{MgCl}_{2}$ or strodotoxin. This suggests that they were secondary to the increase in pontaneous transmitter release. 
TABLE 1

Effect of Guanidine on Membrane Potential and Apparent Membrane Resistance

\begin{tabular}{cccccc}
\hline $\begin{array}{c}\text { Concentration } \\
(\mathrm{mM})\end{array}$ & Cell $^{a}$ & $\begin{array}{c}E_{\mathrm{m}}{ }^{\mathrm{b}} \\
(\mathrm{mV})\end{array}$ & $\begin{array}{c}\Delta E_{\mathrm{M}}{ }^{\mathrm{c}} \\
(\mathrm{mV})\end{array}$ & $\begin{array}{c}R_{\mathrm{m}}{ }^{b} \\
(\mathrm{M} \Omega)\end{array}$ & $\begin{array}{c}\Delta R_{\mathrm{m}}{ }^{c} \\
(\mathrm{M} \Omega)\end{array}$ \\
\hline 0.5 & 1 & -75 & +3 & 45 & -5 \\
0.5 & 2 & -77 & 0 & $* d$ & $*$ \\
1 & 4 & -40 & -1 & 17 & +2 \\
1 & 2 & -77 & +2 & $*$ & $*$ \\
1 & 5 & -51 & +1 & $*$ & $*$ \\
2 & 1 & -72 & +2 & 40 & +3 \\
2 & 8 & -80 & +5 & $*$ & $*$ \\
2 & 9 & -68 & 0 & 16 & +7 \\
\hline
\end{tabular}

${ }^{a}$ Data analysis has been restricted to the six cells whose membrane potential was stable enough to allow accurate estimation of the resting membrane potential.

${ }^{\circ} E_{\mathrm{m}}=$ resting membrane potential; $R_{\mathrm{m}}=$ resting membrane resistance (calculated from the amplitude of electrotonic potentials produced by constant-current pulses).

c $\Delta E_{\mathrm{m}}$ and $\Delta K_{\mathrm{m}}=$ changes in membrane potential and resistance respectively; measured between 5 and $15 \mathrm{~min}$ after application of guanidine.

${ }^{d}$ Not measured.

\section{Extracellular Recording}

Field Potentials. Stimulation of the LOT produced a characteristic surface-negative field potential lasting about $25 \mathrm{~ms}$. As described previously $(23,32)$ this field potential $(\mathrm{N}$-wave) is thought to represent the population EPSP generated in the superficial dendrites of the pyramidal neurons.

Addition of guanidine to the superfusate altered the amplitude and duration of the field potential in a concentration-dependent manner ( 10 preparations tested). After at least a 10-min application, $300 \mu \mathrm{M}$ guanidine increased the amplitude of the $\mathrm{N}$-wave by $14 \pm 5 \%$ (mean $\pm \mathrm{SD} ; N=4)$; $500 \mu \mathrm{M}$ (Fig. 6A) increased the amplitude by $28 \pm 7 \%(N=3)$. Both concentrations also induced a late surface negative potential (Fig. 6A). This effect was reversible by washing for about $20 \mathrm{~min}$. A 60 -min application of $100 \mu \mathrm{M}$ guanidine was without effect (three experiments). Higher concentrations $(\geqslant 1 \mathrm{mM})$ had more complex effects. After a few minutes superfusion, we observed a clear increase in $\mathrm{N}$-wave amplitude (Fig. 6B) associated with the appearance of a large, long-duration, late surfacenegative potential $(\approx 1 \mathrm{~s})$. Continued application of guanidine then resulted in a reduction in $\mathrm{N}$-wave amplitude, whereas the duration of the late potential continued to increase (Fig. 6B). In addition we sometimes 


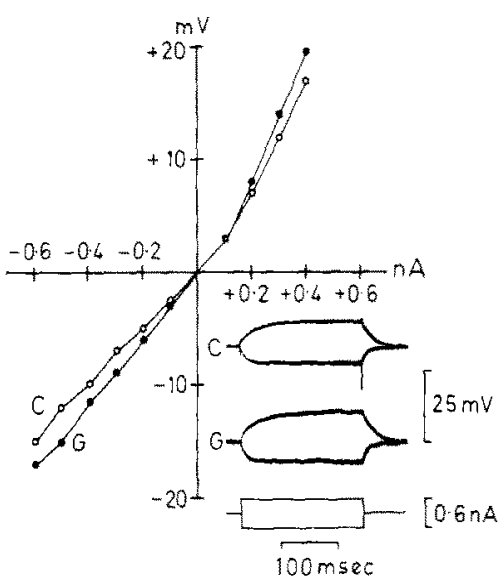

FIG. 4. Current-voltage relationships measured before $(O)$ and $40 \mathrm{~min}$ after $(-$ ) addition of $2 \mathrm{~mm}$ guanidine. During this time, the cell depolarized by $1 \mathrm{mV}$ and the resistance rose slightly. The insets (bottom right) show examples of electronic potentials produced by injecting current through the microelectrode: $\mathrm{C}$-control, $\mathrm{G}$-during guanidine. Resting potential was $-72 \mathrm{mV}$.

observed rhythmic DC oscillations following a single LOT stimulus, which strongly resembled those observed intracellularly. The effects of high concentrations of guanidine were slowly reversible by washing for several hours.

Lateral Olfactory Tract. Recordings from the isolated lateral olfactory tract revealed that $500 \mu \mathrm{M}$ guanidine prolonged the duration of the fiber sopulation action potential by $19 \pm 6 \%(N=5)$ with little or no change in implitude (Fig. 6C). Higher concentrations caused a more marked rolongation with some decrease in amplitude. These effects were slow in onset ( 5 to $15 \mathrm{~min}$ ) and were slowly reversible by washing. $\mathrm{MgCl}_{2}(15 \mathrm{mM})$ lid not reverse the action of guanidine on the LOT; however. tetrodotoxin :ompletely abolished conduction.

\section{DISCUSSION}

The results suggest that guanidine can facilitate spontaneous and timulus-induced release of neurotransmitter substances in the guinea pig solated olfactory cortex. This conclusion is in general agreement with the escribed actions of guanidine on central and peripheral synaptic ansmission in higher and lower vertebrates.

The spontaneous postsynaptic potentials which we observed during uanidine application appear similar to miniature end-plate potentials and 


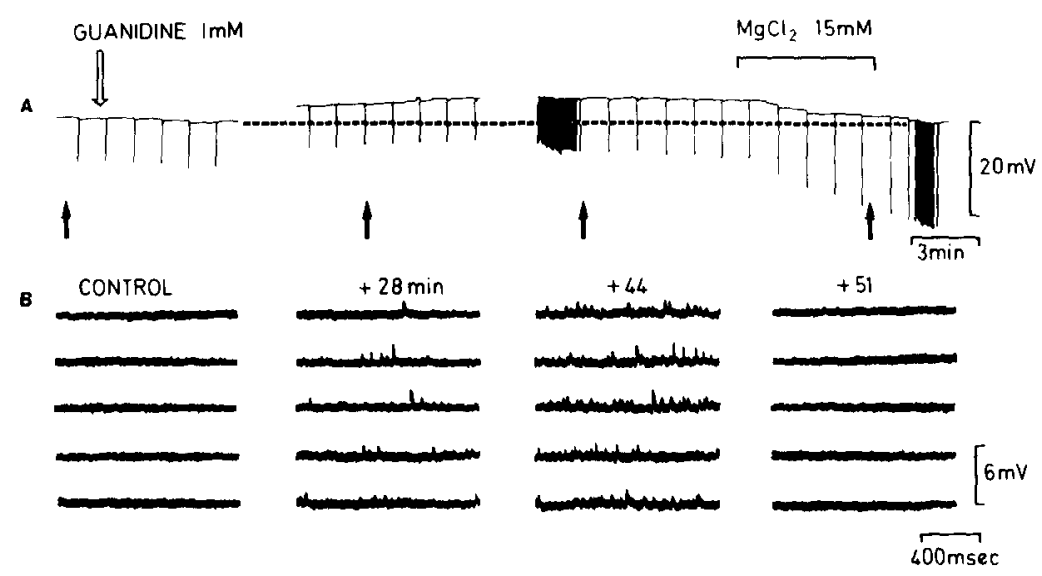

FIG. 5. Effect of guanidine (1 $\mathrm{mm}$ ) on the membrane potential of an olfactory cortex neuron recorded (A) at low amplification and slow speed on a potentiometric recorder and $(B)$ at high amplification and fast speed on an oscilloscope. The downward deflections in $A$ are the membrane responses to negative intracellular current pulses $(300 \mathrm{~ms}, 0.5 \mathrm{nA}, 0.025 \mathrm{~Hz})$; the higher frequency of current pulses (at $+40 \mathrm{~min}$ and $+53 \mathrm{~min}$ ) was used to adjust bridge balance. Guanidine application was started at the point indicated by the open arrow and the horizontal bar indicates the duration of $\mathrm{MgCl}_{2}$ superfusion. The oscilloscope records in $\mathrm{B}$ were taken before, 28,44 , and $51 \mathrm{~min}$ after the start of guanidine application and the solid arrows indicate these times in the recording in A. Guanidine did not immediately alter the resting potential (indicated by the dashed line), but after some time there was a depolarization of about $5 \mathrm{mV}$ and an increase in the amplitude and frequency of spontaneously occurring postsynaptic potentials. Both these effects were reversed by $15 \mathrm{mM} \mathrm{MgCl}_{2}$.

miniature postsynaptic potentials recorded from frog motoneurons $(4,12)$. These are both characterized by the fact that their frequency and amplitude are relatively unaffected by $\mathrm{MgCl}_{2}$ and TTX $(4,12)$. In our experiments, both these compounds abolished guanidine-induced spontaneous potentials suggesting that these are not generated by the mechanism responsible for the occurrence of miniature potentials. This confirms the findings of Grafe and Sonnhof (8), who showed that in high- $\mathrm{Mg}^{2+}$ solution, guanidine did not alter the frequency and amplitude of spontaneously occurring postsynaptic potentials in frog motoneurons.

Matthews and Wickelgren (18) suggested that the occurrence of guanidine-induced spontaneous potentials results from an increased excitability in axons and/or nerve terminals leading to spontaneous action potentials. This theory could explain the occurrence of "giant potentials" at the frog neuromuscular junction $(18,22)$ and is also consistent with our findings that TTX abolished guanidine-induced potentials. Such an increased excitability in presynaptic structures of a neuronal circuit may 

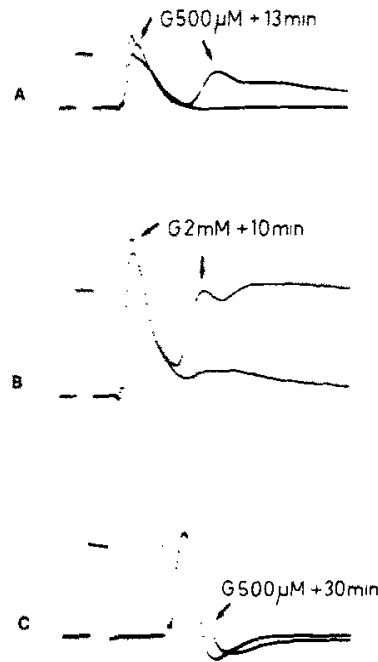
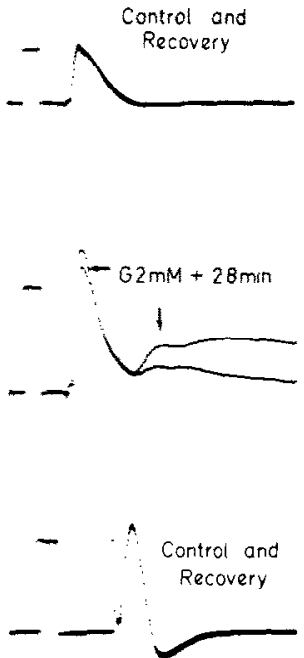

FiG, 6. $A$ and $B$-effects of guanidine on extracellularly recorded field potentials evoked by supramaximal stimulation of the lateral olfactory tract $(50 \mathrm{~V}, 0.1 \mathrm{~ms}, 0.033 \mathrm{~Hz})$. Each trace is the average of 10 responses; the calibration pulse was $10 \mathrm{~ms}, 5 \mathrm{mV}$. The left panel in A shows the potential recorded after $13 \mathrm{~min}$ in $500 \mu \mathrm{M}$ guanidine superimposed over the control. Note the increase in amplitude and the marked late negative potential. These effects were reversed after $65 \mathrm{~min}$ of washing (right panel). The left panel in B shows the potential recorded after 10 $\min$ in $2 \mathrm{mM}$ guanidine superimposed over the control. After $28 \mathrm{~min}$ (right panel), the increase in amplitude produced by guanidine was reversed to a decrease; the amplitude of the late negative potential was also reduced. $\mathrm{C}$ - prolongation of the lateral olfactory tract compound action potential by $500 \mu \mathrm{M}$ guanidine. The isolated tract was stimulated at $50 \mathrm{~V}, 0.1 \mathrm{~ms}, 0.33$ $\mathrm{Hz}$ and each trace is the average of 10 responses; the calibration pulse was $1 \mathrm{~ms}, 1 \mathrm{mV}$. The left panel shows the response recorded after $30 \mathrm{~min}$ in guanidine superimposed over the control. The prolongation was an effect reversible after $60 \mathrm{~min}$ of washing (right panel).

also explain the occurrence of afterdischarges, which we observed during the action of higher concentrations of guanidine.

The prolonged postsynaptic potentials recorded intra- and extracellu'arly during exposure to guanidine, after a single orthodromic stimulus, are nost probably due to an increased amount of neurotransmitter released. This accords with observations made on neuromuscular junctions, where zuanidine was found to increase the quantal release of acetylcholine $(10,11$, $[8,22,30)$. Although the mechanism of this effect is unknown as yet, it is 'ossible that the increased duration of the LOT action potential, which we neasured, could contribute to a facilitation of transmitter release in the Ifactory cortex. Indeed, it has also been shown that guanidine increases ction potential duration in other excitable tissues such as mouse skeletal 
muscle (10) and lamprey spinal cord (18). However, intracellular recordings from pre- and postsynaptic sites in the chick ciliary ganglion indicated that the effect of guanidine on transmitter release was independent of alterations in the presynaptic spike (1). Furthermore, at neuromuscular junctions pretreated with TTX to block action potentials, transmitter release induced by electrotonic depolarization of nerve terminals was also facilitated by guanidine (16).

Therefore it cannot be concluded that a prolongation of the presynaptic action potential is the only reason for the enhanced release of transmitter, and it may be possible that an increase in the amount of free $\mathrm{Ca}^{2+}$ in presynaptic nerve terminals may play an important role $(16,18)$.

Another possible explanation for the prolongation of synaptic potentials is that guanidine may interact with postsynaptic receptors and/or ion channels. Such an interaction was proposed for pentobarbital, which also greatly prolongs synaptic potentials in the isolated olfactory cortex (28). As yet we cannot exclude this possibility, but it seems unlikely in view of the fact that at the neuromuscular junction, guanidine only increased stimulus-induced acetylcholine release and did not alter the response to acetylcholine iontophoretically applied to the muscle fiber $(10,22)$. Further evidence against an interaction with postsynaptic receptors stems from our observation that guanidine hardly altered resting membrane potential and resistance, in agreement with observations on frog motoneurons (8), neuromuscular junctions $(10,18,30)$, and chick ciliary ganglion (1).

Our results indicate that guanidine probably enhances excitatory and inhibitory processes in an unspecific manner. Facilitation of excitatory transmission is suggested by the increased amplitude of the extracellularly recorded population EPSP in addition to intracellular recordings, which showed that, in guanidine, some neurons either fired more than one action potential in response to a single orthodromic stimulus or exhibited spontaneous afterdischarges. On the other hand, the marked prolongation of the IPSP (Fig. 1D) strongly suggests an increased release of inhibitory transmitter.

Recently, the serum concentration of guanidine was measured in healthy humans after oral administration (19). From these data it was calculated that after 2 days of dosage $[3 \times 1 \mathrm{~g} /$ day; the maximum clinically used dose (17)], the serum concentration would be 400 to $650 \mu \mathrm{M}$ (W. Mayer, personal communication). The fact that in our experiments concentrations of guanidine $\geqslant 300 \mu \mathrm{M}$ were effective in enhancing synaptic transmission, suggests that effects observed in the guinea pig isolated olfactory cortex may resemble those occurring in the human brain. If this is so, the following 
points may help to explain the beneficial action of guanidine in human central nervous system diseases. (a) An increase in stimulus-induced transmitter release might help to overcome a reduction in the efficiency of synaptic transmission. (b) An enhancement of spontaneous transmitter release may exert a beneficial trophic action on postsynaptic receptors. (c) An increased excitability of single fibers as described for frog motor nerves and lamprey Müller axons (18) could improve conduction in degenerating nerve fibers. Finally, the paresthesia observed during guanidine treatment $(17,20)$ could be due to spontaneous potentials in cutaneous receptors as recorded in the toad $(25)$.

However, in view of the fact that at present nothing is known about changes in synaptic function or postsynaptic receptors in amyotrophic lateral sclerosis or spinal muscular atrophy, these ideas remain speculative.

\section{REFERENCES}

1. BanKs, F. W. 1978. The effect of guanidine on transmitter release in the ciliary ganglion of the chick. J. Physiol. (London) 278: 425-433.

2. BRoWN, D. A., AND M. GALVAN, 1979. Responses of the guinea-pig isolated olfactory cortex slice to $\gamma$-aminobutyric acid recorded with extracellular electrodes. $B r . J$. Pharmacol. 65: 347-353.

3. Cherington, M. 1974. Botulism. Ten-year experience. Arch. Neurol. 30: 432-437.

4. Erulkar, S. D., G. E. Dambach, and D. MEnder. 1974. The effect of magnesium at motoneurones of the isolated spinal cord of the frog. Brain Res. 66: 413-424.

5. FENG, T. P. 1938. Studies on the neuromuscular junction. X. The effects of guanidine. Chin. J. Physiol. 13: 119-140.

6. Galvan, M., P. Grafe, and G. ten Bruggencate. 1979. Guanidine-induced facilitation of transmitter release in mammalian olfactory cortex slices demonstrated by intracellular recording. In Proc. First International Colloquium on Receptors, Neurotransmitters and Peptide Hormones, Capri, Italy. Raven Press, New York (in press).

7. Gergens, E., And E. Baumann. 1876. Über das Verhalten des Guanidin, Dicyandiamidin und Cyanamid im Organismus. Arch. Ges. Physiol. 12: 205-214,

8. GRAFE, P., AND U. SONNHOF. 1977. Effects of guanidine on synaptic transmission in the spinal cord of the frog. Naunyn-Schmiedeberg's Arch. Pharmacol. 301: 129-134.

9. Hofmann, W. W., R. L. Parsons, and G. A. Feigen. 1966. Effects of temperature and drugs on mammalian motor nerve terminals. Am. J. Physiol. 211: 135-140.

10. Kamenskaya, M. A., D. ElmQvist, and S. TheslefF. 1975. Guanidine and neuromuscular transmission. 1. Effect on transmitter release occurring spontaneously and in response to single nerve stimuli. Arch. Neurol. 32: 505-509.

11. Kamenskaya, M. A., D. ElmQvist, And S. Thesleff, 1975. Guanidine and neuromuscular transmission. 2. Effect on transmitter release in response to repetitive nerve stimulation. Arch. Neurol. 32: 510-518.

12. KATZ, B., AND R. MLEDI. 1963. A study of spontaneous miniature potentials in spinal motoneurones. $J$. Physiol. 168: $389-422$. 
13. KoIzUmi, K. 1955. Tetanus and hyperresponsiveness of the mammalian spinal cord produced by strychnine, guanidine, and cold. Am. J. Physiol. 183: 35-43.

14. LAMBERT, E. H., AND D. ELMQVIST. 1971. Quantal components of endplate potentials in the myasthenic syndrome. Ann. N.Y. Acad. Sci. 183: 183-199.

15. LUNDH, H., S. LEANDER, AND S. THESLEFF. 1977. Antagonism of the paralysis produced by botulinum toxin in the rat. The effects of tetraethylammonium, guanidine and 4-aminopyridine. J. Neurol. Sci. 32: 29-43.

16. Lundh, H., AND S. TheslefF. 1977. The mode of action of 4-aminopyridine and guanidine on transmitter release from motor nerve terminals. Eur. J. Pharmacol, 42: 411-412.

17. Maida, E., F. Gerstentrand, E. Gründig, and H. Binder. 1978. The application of guanidine hydrochloride to the treatment of degenerative nervous and muscular diseases. 1. Clinical Results. Wien. Klin. Wochenschr. 90: 43-48.

18. MatThews, G., AND W. O. WiCKelGREN. 1977. Effects of guanidine on transmitter release and neuronal excitability. J. Physiol. (London) 266: 69-89.

19. MAYer, W., AND A. Komarek. 1978. A contribution to the pharmacodynamics of guanidine-hydrochloride. Drug Res. 28: 680-681.

20. Norris, F. H., P. R. Calanchini, R. J. Fallat, S. Panchari, and B. Jewett. 1974. The administration of guanidine in amyotrophic lateral sclerosis. Neurology (Minneapolis) 24: 721-728.

21. OH, S. J., AND K. W. KIM. 1973. Guanidine hydrochloride in the Eaton-Lambert syndrome. Electrophysiologic improvement. Neurology (Minneapolis) 23: 1084-1090.

22. Otsuka, M., AND M. ENDo. 1960. The effect of guanidine on neuromuscular transmission. J. Pharmacol. Exp. Ther. 128: 273-282.

23. Richards, C. D., AND R. SeRCombe. 1968. Electrical activity observed in guinea-pig olfactory cortex maintained in vitro. J. Physiol. (London) 197: 667-683.

24. RiCKer, K., AND W. DöLl. 1970. Treatment of botulism with guanidine. Z. Neurol. 198: $332-341$.

25. SAto, M. 1953. Pseudoreflex from endplate and sensory nerve endings. J. Neurophysiol. 16: $101-115$.

26. Scholfield, C. N. 1978. Electrical properties of neurones in the olfactory cortex in vitro. J. Physiol. (London) 275: 535-546.

27. SCHOLFIELD, C. N. 1978. A depolarizing inhibitory potential in neurones of the olfactory cortex in vitro. J. Physiol. (London) 275: 547-558.

28. SCholfiei.D, C. N. 1978. A barbiturate induced intensification of the inhibitory potential in slices of guinea-pig olfactory cortex. J. Physiol. (London) 275: 559-566.

29. Steinböck, H., H. Binder, F. Gerstenbrand, E. Pilz, and E. Maida. 1977. The efficacy of guanidine hydrochloride in the treatment of Werdnig-Hoffmann disease. Wien. Klin. Wochenschr. 89: 269-272.

30. TERÄVÄINEN, H., AND A. LARSEN. 1975. Effect of guanidine on quantal release of acetylcholine in the mammalian myoneural junction. Exp. Neurol. 48: 601-609.

31. WIEDERHOLT, W. C. 1975. Guanidine hydrochloride therapy in neuromuscular disorders. West. J. Med. 123: 132-133.

32. Yamamoto, C., ANd H. Mcllwain. 1966. Electrical activities in thin sections from mammalian brain in chemically-defined media in vitro. J. Neurochem. 13: 1333-1343. 